\title{
Predicting an Unfavorable Course of Dizziness in Older Patients
}

Hanneke Stam, MD ${ }^{1}$

Otto R. Maarsingh, $M D, P b D^{1}$

Martijn W. Heymans, $P b D^{2}$

Henk C.P.M. van Weert, MD, PbD

Jobannes C. van der Wouden, $P b D^{1}$

Henriëtte E. van der Horst, $M D, P b D^{1}$

'Department of General Practice and Elderly Care Medicine, Amsterdam Public

Health Research Institute, Amsterdam UMC, Vrije Iniversiteit Amsterdam,

Amsterdam, The Netherlands

${ }^{2}$ Department of Clinical Epidemiology and Biostatistics, Amsterdam UMC, Vrije Iniversiteit Amsterdam, Amsterdam, The Netherlands

${ }^{3}$ Department of General Practice, Amsterdam UMC, University of Amsterdam, Amsterdam,

The Netherlands

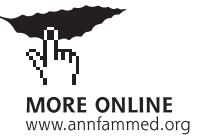

Conflicts of interest: authors report none.

\section{CORRESPONDING AUTHOR}

Hanneke Stam, MD

VU University Medical Center

Department of General Practice and Elderly

Care Medicine and Amsterdam Public

Health Research Institute

Van der Boechorststraat 7

1081 BT Amsterdam, The Netherlands

stam.h@vumc.nl

\begin{abstract}
PURPOSE Because dizziness in older people is often chronic and can substantially affect daily functioning, it is important to identify those at risk for an unfavorable course of dizziness to optimize their care. We aimed to develop and externally validate a prediction model for an unfavorable course of dizziness in older patients in primary care, and to construct an easy-to-use risk prediction tool.
\end{abstract}

METHODS We used data from 2 prospective cohorts: a development cohort with 203 patients aged 65 years or older who consulted their primary care physician for dizziness and had substantial dizziness-related impairment (Dizziness Handicap Inventory $[\mathrm{DHI}] \geq 30$ ), and a validation cohort with 415 patients aged 65 years or older who consulted their primary care physician for dizziness of any severity. An unfavorable course was defined as presence of substantial dizzinessrelated impairment $(\mathrm{DHI} \geq 30)$ after 6 months.

RESULTS Prevalence of an unfavorable course of dizziness was $73.9 \%$ in the development cohort and $43.6 \%$ in the validation cohort. Predictors in the final model were the score on the screening version of the DHI, age, history of arrhythmia, and looking up as a provoking factor. The model showed good calibration and fair discrimination (area under the curve $=0.77$ ). On external validation, discriminative ability remained stable (area under the curve $=0.78$ ). The constructed risk score was strongly correlated with the prediction model. Performance measures for risk score cut-off values are presented to determine the optimal cut-off point for clinical practice.

CONCLUSIONS We developed an easy-to-use risk score for dizziness-related impairment in primary care. The risk score, consisting of only 4 predictors, will help primary care physicians identify patients at high risk for an unfavorable course of dizziness.

Ann Fam Med 2018;16:428-435. https://doi.org/10.1370/afm.2289.

\section{INTRODUCTION}

$\mathrm{O}$ ne out of 10 older patients visits their primary care physician at least once a year because of dizziness. ${ }^{1,2}$ Dizziness strongly affects daily functioning in older adults ${ }^{3-6}$ and is associated with increased depressive symptoms, lower self-rated health, and reduced social activities. ${ }^{3,7}$ Furthermore, older dizzy people have an increased risk of falling. ${ }^{8}$

Dizziness can refer to several sensations including a giddy or rotational sensation, a loss of balance, a faint feeling, light-headedness, instability or unsteadiness, a tendency to fall, or a feeling of everything turning black. ${ }^{9}$ Dizziness is often divided into 4 subtypes: vertigo, presyncope, disequilibrium, and other dizziness. ${ }^{10}$ Defining the subtype might help the physician to get a grip on the cause. Yet, categorizing dizziness is difficult in older patients because many report more than 1 subtype. ${ }^{11-14}$

Most guidelines on dizziness promote a diagnosis-oriented approach, starting with a search for its cause followed by treatment once the underlying illness has been diagnosed. ${ }^{15,16}$ Dizziness mostly has a benign origin. Potential life-threatening illness, such as stroke or a brain tumor, 
is rare. If an accurate diagnosis of dizziness can be established, there is potential for effective treatment. Examples are the Epley maneuver for benign paroxysmal positional vertigo, ${ }^{17,18}$ and vestibular rehabilitation for vertigo persisting after the Epley maneuver. ${ }^{19}$ Dizziness in older people is, however, often a diagnostic challenge for physicians because it can refer to a variety of sensations, as there are many potential underlying causes, and there is often a multifactorial origin. ${ }^{9,13}$ As a result, primary care physicians often manage dizziness in this age-group with a wait-andsee strategy, ${ }^{2}$ although they could also focus on targeting potential contributing factors such as multiple drug use or depressive symptoms. , $^{93,20-27}$ Identification of patients with an unfavorable prognosis, even those with an unknown cause of dizziness, may contribute to better care, for example, by targeting potential contributing factors to dizziness in patients with an unfavorable dizziness prognosis. ${ }^{9,13,20-27}$

Only a single study has presented a prediction model to assess dizziness prognosis in older patients. ${ }^{24}$ Yet, the researchers choose to exclude the strongest predictor, dizziness-related impairment as measured with the Dizziness Handicap Inventory (DHI), from their final prediction model because the score does not indicate causal mechanisms and therefore does not provide clues for treatment. ${ }^{24} \mathrm{~A}$ prediction model to identify older patients at high risk for an unfavorable course of dizziness that includes the DHI score as predictor may have an impact on health care, as it helps to discriminate those in need of intervention. The aim of this study was to develop and externally validate a prediction model for an unfavorable course of dizziness in older people in primary care, with dizziness-related impairment as a starting point. Using this prediction model, we aimed to construct an easy-to-use risk score for identifying older adults at high risk for an unfavorable course of dizziness.

\section{METHODS}

\section{Development Cohort}

We collected data for model development in a prospective observational cohort study having a 6 -month follow-up, as part of the Reduction Of Dizziness in older pEOple (RODEO) study. A detailed description of the study protocol has been published elsewhere. ${ }^{28}$

Participants were recruited from 45 primary care practices in the Netherlands between January 2015 and July 2016. Inclusion criteria were age 65 years or older, consultation of the primary care physician for dizziness in the preceding 3 months, and having substantial dizziness-related impairment (DHI score of 30 or higher). ${ }^{29}$ Patients with severe cognitive impairment, terminal illness, severe psychiatric problems, or inability to speak Dutch were excluded.

Sample size calculation was based on the commonly used minimum of 10 patients with the outcome per predictor ${ }^{30}$ and on our intention to develop a risk score with a maximum of 10 predictors. With the assumption that $60 \%$ of the patients probably would have an unfavorable outcome after 6 months of follow-up, ${ }^{14}$ we needed at least 170 participants.

\section{Validation Cohort}

To validate the prediction model in an external cohort, we used data from the Dizziness In Elderly Patients (DIEP) study. ${ }^{24} \mathrm{~A}$ total of 415 patients from 24 primary care practices in the Netherlands enrolled in this study between July 2006 and January 2008. Inclusion criteria were age 65 years or older and consulting the primary care physician because of dizziness. In contrast to the case for the development cohort, substantial dizzinessrelated impairment was not an inclusion criterion in this cohort. Exclusion criteria were inability to speak

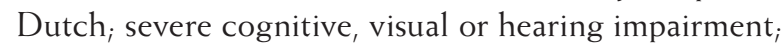
and wheelchair dependency.

\section{Outcome Measure}

The outcome, an unfavorable course of dizziness, was defined as substantial dizziness-related impairment at 6 months of follow-up. Dizziness-related impairment was assessed with the DHI ${ }^{29}$ A DHI score of 30 or higher correlates with substantial dizziness-related impairment. ${ }^{24,29,31,32}$ The DHI is a widely used self-report questionnaire that is designed to quantify the impact of dizziness on everyday life. It consists of 25 items. The DHI score (range $=0$ to 100 ) is obtained by summing ordinal scale responses-yes (4), sometimes (2), no (0) — with higher total score corresponding to more severe dizziness-related impairment. Previous studies have shown good construct validity, high internal consistency, and satisfactory test-retest reliability. ${ }^{29,32}$

\section{Candidate Predictors}

We aimed to develop an easy-to-use risk score with predictors that can readily be assessed during consultations in primary care. Selection of candidate predictors was therefore based on previous research and feasibility. $913,14,20-27,33$ Candidate predictors were self-reported and spanned 3 domains: demographic (6 variables), health status (28 variables), and dizziness (33 variables). Dizziness-related impairment at baseline was assessed with both the full 25 -item $\mathrm{DHI}^{29}$ and the 10 -item screening version of the DHI (DHI-S). ${ }^{34}$ Supplemental Appendix 1, http://www.annfammed. org/content/16/5/428/suppl/DC1, provides a complete overview of candidate predictors. 


\section{Model Development}

We performed a univariate logistic regression analysis to assess the association between candidate predictors and outcome. Associated variables with $P<.10$ were included in a multivariate logistic regression model. Continuous variables were checked for linearity. Through backward selection, candidate predictors with $P>.157$ were excluded from the multivariate logistic regression model. ${ }^{35}$

We imputed missing data on variables having less than $5 \%$ missing values using single stochastic imputation. ${ }^{36}$ Multiple imputation using the chained equation method was performed when a variable was missing $5 \%$ of values or more, with 10 imputations in the case of $5 \%$ to $10 \%$ missing values and 15 imputations in the case of $10 \%$ to $15 \%$ missing values. ${ }^{36}$ Two deceased patients were excluded from the analysis.

The prediction model was developed in the combined multiple imputed data sets of the development cohort, applying the Rubin rules for pooling results. ${ }^{37}$ A prediction model with a dichotomous outcome is very useful in daily clinical practice because the outcome is easy to interpret for primary care physicians: a patient is either at high risk or at low risk for an unfavorable course of dizziness. Yet, converting a continuous outcome measure into a dichotomous outcome might result in information loss. ${ }^{38}$ We therefore developed an additional prediction model introducing dizziness-related impairment, also assessed with the DHI, as a continuous outcome. Other than performing linear regression analyses instead of logistic regression analyses, we applied the same methods as we did when constructing the original prediction model.

\section{Model Performance}

We assessed model performance by applying calibration and discrimination tests. Calibration refers to the agreement between observed endpoints and probabilities predicted by the model. ${ }^{39}$ Calibration can be assessed graphically by plotting the observed outcome frequencies against the predicted probabilities. Calibration was also assessed with the Hosmer-Lemeshow goodness-of-fit statistic. Discrimination is the ability of the model to differentiate between patients with and without an unfavorable dizziness course. Discrimination was assessed with the area under the receiver operating characteristic curve (AUC). To estimate the potential for overfitting and optimism in model performance we internally validated the model using bootstrapping techniques. ${ }^{40}$ Overoptimism (if present) was corrected for by adjusting the regression coefficients with a slope value retrieved on internal validation and by calculating a new intercept thereafter via an offset procedure.
For external validation, we used the fixed coefficients of the developed model and assessed calibration and discrimination of the model in the validation cohort. In case of poor performance we planned to update the model by adjustment of the intercept. ${ }^{41}$

We assessed model performance in the multiple imputed data sets of the development cohort and validation cohort. Calibration plots, Hosmer-Lemeshow statistics, receiver operating characteristic curves, and AUCs were generated in all separate data sets of the multiple imputed data sets. Subsequently, HosmerLemeshow statistics were pooled, and the median and interquartile range (IQR) of the AUCs were calculated. Calibration plots and receiver operating characteristic curves from separate data sets of the multiple imputed data sets are presented.

\section{Risk Score}

We converted the prediction model to a risk score by dividing each regression coefficient by the lowest regression coefficient. Agreement between the prediction model and the risk score was assessed with the Pearson correlation coefficient. Sensitivity, specificity, and predictive values were calculated for different risk score cut-off values to determine the optimal cut-off point for daily clinical practice. A cut-off point was generated from the validation sample as this cohort comprises patients the primary care physician will encounter in daily practice: dizzy patients having mild to severe dizziness-related impairment. The cut-off point was set at a score with a high specificity because we wanted to avoid large numbers of false-positives.

Statistical analyses were performed with SPSS 22.0 (SPSS Inc) and R software (R Foundation for Statistical Computing). For reporting this prediction and validation study, we used the Transparent Reporting of a multivariable prediction model for Individual Prognosis Or Diagnosis (TRIPOD) Statement. ${ }^{42}$

The study was approved by the Medical Ethics Review Committee of VU University Medical Center Amsterdam (approval number: NL49604.029.14).

\section{RESULTS}

\section{Patients and Model Development}

Prevalence of the outcome, that is, an unfavorable course of dizziness at 6 months of follow-up, was $73.9 \%$ among the 203 patients in the development cohort and $43.6 \%$ among the 415 patients in the validation cohort. Table 1 provides an overview of characteristics for both cohorts. For 6 potential candidate predictors in the development cohort, values were missing $(\leq 4 \%$ missing for the DHI-S score, any psychiatric illness, depressive disorder, anxiety disorder, 
Table 1. Baseline Characteristics of Patients in the Development and Validation Cohorts

\begin{tabular}{lcc}
\hline Characteristic & $\begin{array}{c}\text { Development } \\
\text { Cohort } \\
\text { (n = 203) }\end{array}$ & $\begin{array}{c}\text { Validation } \\
\text { Cohort } \\
\text { (n = 415) }\end{array}$ \\
\hline Unfavorable dizziness course, ${ }^{\text {a No. (\%) }}$ & $150(73.9)$ & $181(43.6)$ \\
Female, No. (\%) & $127(62.6)$ & $305(73.5)$ \\
Age, mean (SD), y & $77.5(7.0)$ & $78.5(7.1)$ \\
Number of chronic diseases, mean (SD) & $1.8(1.4)$ & $2.1(1.4)$ \\
Number of drugs used, mean (SD) & $5.5(3.6)$ & $4.4(3.0)$ \\
Dizziness characteristics & & \\
DHI score, ${ }^{b}$ mean (SD) [range] & $46.2(13.4)[30-88]$ & $36.1(19.9)[0-88]$ \\
Time since onset of dizziness, No. (\%) & & \\
0-4 weeks & $3(1.5)$ & $29(7.0)$ \\
1-6 months & $34(16.7)$ & $98(23.6)$ \\
6-48 months & $49(24.1)$ & $109(26.3)$ \\
2-10 years & $74(36.5)$ & $120(28.9)$ \\
$>10$ years & $42(21.2)$ & $59(14.2)$ \\
Description of dizziness, No. (\%)c & & \\
Instability or unsteadiness & $162(79.8)$ & $280(67.5)$ \\
Loss of balance & $165(81.3)$ & $287(69.2)$ \\
Lightheadedness & $145(71.4)$ & $247(59.5)$ \\
Rotational sensation & $137(67.5)$ & $228(54.9)$ \\
Tendency to fall & $135(66.5)$ & $225(54.2)$ \\
Giddy & $115(56.7)$ & $176(42.2)$ \\
Environment spinning & $84(41.4)$ & $137(33.0)$ \\
Becoming unwell & $60(29.6)$ & $114(27.5)$ \\
Near faint & $59(29.1)$ & $96(23.1)$ \\
Everything turning black & $39(19.2)$ & $68(16.4)$ \\
\hline DHI = Dizziness Handicap Inventory. & & \\
a At 6 months of follow-up. & & \\
b Score ranges from 0 to 100, with higher scores indicating more severe dizziness-related \\
impairment. & & \\
'Adds up to more than 100\% because more than 1 answer was allowed. & \\
\hline
\end{tabular}

factor (Table 2). History of arrhythmia and looking up as provoking factor were assessed during an interview with the questions "Do you have a history of arrhythmia?" and "Does looking up provoke your dizziness?" Table 3 shows the prevalence of the predictors in the development and validation cohorts. The prediction model with the DHI as a continuous instead of a dichotomous outcome is presented in Supplemental Appendix 2 (http://www.annfammed.org/ content/16/5/428/suppl/DC1).

\section{Model Performance}

Calibration of the prediction model was adequate, with a nonsignificant Hosmer-Lemeshow statistic $(P=.63)$. The calibration plot showed good agreement between predicted and observed numbers of patients having an unfavorable course of dizziness (Supplemental Appendix 3A, http://www.annfammed.org/ content/16/5/428/supp1/DC1). Discriminative ability of the model was fair, with an AUC of 0.77 (IQR, 0.76-0.78). On internal validation, the model also performed adequately (Hosmer-Lemeshow statistic $P=.75$, AUC $=0.75 ; \mathrm{IQR}, 0.74-0.75)$. We corrected for overoptimism of the original model by multiplying all regression coefficients with a slope value of 0.90 and subtracting 0.698 from the intercept.

On external validation, performance of the adjusted model remained stable (AUC $=0.78$; IQR, 0.78-0.79) but calibration deteriorated (Supplemental Appendix 3B, http://www.annfammed.org/ and impaired functional mobility; $9.4 \%$ missing for the DHI score [Supplemental Appendix 1]). Outcome information was missing for $11.4 \%$ of patients in the development cohort and for $9.6 \%$ of patients in the validation cohort

Ten candidate predictors were associated with the outcome in univariate analysis (Supplemental Appendix 1). Two of these 10 candidate predictors were the DHI score and the DHI-S score, both of which quantify dizziness-related impairment. Because the DHI score and the DHI-S score both measure the same concept, we choose to construct 2 models: 1 with the DHI score and 1 with the DHI-S score. As both models performed almost equally, we chose the model including the DHI-S score for feasibility reasons.

Predictors in the final prediction model were the DHI-S score, age, history of arrhythmia, and looking up as provoking
Table 2. Prediction Model for an Unfavorable Course of Dizziness in Older Adults

\begin{tabular}{|c|c|c|c|}
\hline Predictor & B & OR $(95 \% \mathrm{CI})$ & $\begin{array}{c}P \\
\text { Value }\end{array}$ \\
\hline Intercept & -6.385 & - & - \\
\hline DHI-S score, ${ }^{a}$ per point & 0.127 & $1.14(1.07-1.21)$ & $<.001$ \\
\hline Age, per year & 0.063 & $1.06(1.00-1.13)$ & .04 \\
\hline History of arrhythmiab & 0.661 & $1.94(0.81-4.63)$ & .14 \\
\hline Looking up as provoking factor ${ }^{b}$ & 0.690 & $1.99(0.92-4.32)$ & .08 \\
\hline \multicolumn{4}{|c|}{$\begin{array}{l}\mathrm{B}=\text { regression coefficient; } \mathrm{OR}=\text { odds ratio; } \mathrm{DHI}-\mathrm{S}=\text { screening version of Dizziness Handi- } \\
\text { cap Inventory. }\end{array}$} \\
\hline \multicolumn{4}{|c|}{$\begin{array}{l}\text { Note: Adjusted model on internal validation, linear predictor }=-5.687+(0.115 \times \mathrm{DHI}-\mathrm{S})+ \\
(0.056 \times \text { age })+(0.597 \times \text { history of arrhythmia })+(0.623 \times \text { looking up as provoking factor }) \text {. }\end{array}$} \\
\hline \multicolumn{4}{|c|}{$\begin{array}{l}\text { a Score ranges from } 0 \text { to } 40 \text {, with higher scores indicating more severe dizziness-related } \\
\text { impairment. } \\
\text { b Yes }=1 \text { no }=0\end{array}$} \\
\hline
\end{tabular}


content/16/5/428/suppl/DC1). Yet, recalibration with adjustment of the intercept (intercept of -1.08) resulted in good calibration (Supplemental Appendix 3C, http://www.annfammed.org/content/16/5/428/

Table 3. Predictors in the Development and Validation Cohorts

\begin{tabular}{lcc}
\hline Predictor & $\begin{array}{c}\text { Development } \\
\text { Cohort }\end{array}$ & $\begin{array}{c}\text { Validation } \\
\text { Cohort }\end{array}$ \\
\hline Age, mean (SD), Y & $77.5(7.0)$ & $78.5(7.1)$ \\
DHI-S score, mean (SD) & $17.4(6.9)$ & $13.7(9.3)$ \\
History of arrhythmia & $59(29.1)$ & $39(22.4)$ \\
Looking up as provoking & $129(63.5)$ & $214(51.6)$ \\
factor & & \\
\hline DHI-S = screening version of Dizziness Handicap Inventory. & \\
\hline
\end{tabular}

\section{Table 4. Risk Score for an Unfavorable Course} of Dizziness in Older Adults

\begin{tabular}{|c|c|}
\hline Predictor at Baseline & Score \\
\hline Age in years & $1 \times$ age \\
\hline DHI-S score in points & $2 \times$ DHI-S score \\
\hline \multicolumn{2}{|l|}{ History of arrhythmia } \\
\hline Yes & 11 \\
\hline No & 0 \\
\hline \multicolumn{2}{|c|}{ Looking up as provoking factor } \\
\hline Yes & 11 \\
\hline No & 0 \\
\hline \multicolumn{2}{|c|}{ DHI-S = screening version of the Dizziness Handicap Inventory. } \\
\hline \multicolumn{2}{|c|}{$\begin{array}{l}\text { Note: Risk score is derived by adding all scores. Example: A man aged } 78 \text { years } \\
\text { with a DHI-S score of } 14 \text {, a history of arrhythmia, and looking up not being a } \\
\text { provoking factor for dizziness will have a score of }(78+[2 \times 14]+11+0)=117 \text {. }\end{array}$} \\
\hline \multicolumn{2}{|c|}{$\begin{array}{l}\text { A score of } \geq 134 \text { corresponds to a high risk of an unfavorable course of dizzi- } \\
\text { ness. The risk of an unfavorable course of dizziness is } \geq 77.1 \% \text { for patients with } \\
\text { a score } \geq 134 \text { (see Table } 5 \text { ). }\end{array}$} \\
\hline
\end{tabular}

suppl/DC1, Hosmer-Lemeshow statistic $P=.83$ ). The discriminative ability of the recalibrated model did not change.

\section{Risk Score}

The constructed risk score is presented in Table 4 . We found strong correlations between the modelpredicted probabilities and the risk score in both the development cohort $(r=0.96, P \leq .001)$ and the validation cohort $(r=0.97, P \leq .001)$. Table 5 and Supplemental Appendix 4 (http://www.annfammed.org/ content/16/5/428/suppl/DC1) provide overviews of risk score thresholds and their respective classification measures. A score of 134 or higher corresponds to a high risk of an unfavorable course of dizziness with a specificity of $91.9 \%$. Applying the risk score with a threshold of 134 or higher to the validation cohort, the pretest risk of $43.6 \%$ for an unfavorable course of dizziness rises to a posttest risk of $77.1 \%$, without many patients having false-positive results.

\section{DISCUSSION}

\section{Summary}

Our aim was to develop and externally validate a prediction model for a 6-month unfavorable course of dizziness among older patients in primary care. On the basis of this prediction model, we constructed an easy-to-use risk score for identifying patients at high risk for an unfavorable course of dizziness. The developed prediction model and accompanying risk score consist of 4 easily obtainable predictors: DHI-S score, age, history of arrhythmia, and looking up as a provoking factor. The prediction model performed well, with adequate calibration and fair discrimination

Table 5. Model Predictive Performance in the Validation Cohort at Various Risk Score Thresholds

\begin{tabular}{|c|c|c|c|c|c|c|c|c|}
\hline $\begin{array}{l}\text { Risk Score } \\
\text { Threshold } \\
\text { (Percentage of } \\
\text { Total Sample) }\end{array}$ & $\begin{array}{c}\text { True } \\
\text { Positive, } \\
\text { No. }\end{array}$ & $\begin{array}{l}\text { True } \\
\text { Negative, } \\
\text { No. }\end{array}$ & $\begin{array}{l}\text { False- } \\
\text { Positive, } \\
\text { No. }\end{array}$ & $\begin{array}{l}\text { False- } \\
\text { Negative, } \\
\text { No. }\end{array}$ & $\begin{array}{c}\text { Sensitivity, } \\
\%\end{array}$ & $\begin{array}{c}\text { Specificity, } \\
\%\end{array}$ & $\begin{array}{l}\text { Positive } \\
\text { Predictive } \\
\text { Value, } \%\end{array}$ & $\begin{array}{l}\text { Negative } \\
\text { Predictive } \\
\text { Value, \% }\end{array}$ \\
\hline$\geq 69(100)$ & 181 & 0 & 234 & 0 & 100.0 & na & 43.6 & na \\
\hline$\geq 86(90)$ & 175 & 35 & 199 & 6 & 96.7 & 15.0 & 46.8 & 85.4 \\
\hline$\geq 92(80)$ & 169 & 71 & 163 & 12 & 93.4 & 30.3 & 50.9 & 85.5 \\
\hline$\geq 98(70)$ & 159 & 102 & 132 & 22 & 87.8 & 43.6 & 54.6 & 82.3 \\
\hline$\geq 105(60)$ & 152 & 137 & 97 & 29 & 84.0 & 58.5 & 61.0 & 82.5 \\
\hline$\geq 113(50)$ & 137 & 163 & 71 & 44 & 75.7 & 69.7 & 65.9 & 78.7 \\
\hline$\geq 119(40)$ & 116 & 184 & 50 & 65 & 64.1 & 78.6 & 69.9 & 73.9 \\
\hline$\geq 126$ (30) & 91 & 201 & 33 & 90 & 50.3 & 85.9 & 73.4 & 69.1 \\
\hline$\geq 134$ (20) & 64 & 215 & 19 & 117 & 35.4 & 91.9 & 77.1 & 64.8 \\
\hline$\geq 150(10)$ & 34 & 227 & 7 & 147 & 18.8 & 97.0 & 82.9 & 60.7 \\
\hline$>176(0)$ & 0 & 234 & 0 & 181 & na & 100.0 & na & 56.4 \\
\hline
\end{tabular}


$(\mathrm{AUC}=0.77)$. In the external cohort, discriminative ability of the model remained stable $(\mathrm{AUC}=0.78)$. The risk score was strongly correlated with the prediction model $(r=0.96, P \leq .001)$ and will enable primary care physicians to easily identify patients at high risk for an unfavorable course of dizziness.

\section{Strengths and Limitations}

An important strength of this study is that the developed prediction model and accompanying risk score were built with readily available variables. With only 4 predictors, the model discriminates fairly well between patients with and without high risk for an unfavorable course of dizziness. The primary care physician can derive 1 of the 4 predictors (age) from the patients' medical chart and 2 predictors by asking short questions (history of arrhythmia and looking up as provoking factor). The fourth predictor, DHI-S score, is based on a short questionnaire with 10 multiplechoice questions.

Another strength of this study is the external validation of our prediction model. It is essential to evaluate a model's predictive performance in an independent data set because model performance is generally lower in a new data set than in the initial population. ${ }^{43}$ Moreover, our study showed stable model performance on external validation in a different but related patient subgroup, also referred to as domain validation, which is considered the strongest evidence for the generalizability of a prediction model to new patients. ${ }^{44}$ We purposely selected this subgroup with various dizziness-related impairment for external validation because we consider it to be better representative of the population visiting primary care physicians, in contrast to the development cohort, which included only patients with severe dizzinessrelated impairment.

This study also has some limitations. First, the development cohort was a selected population of patients willing to participate in a cluster-randomized trial (the RODEO study). ${ }^{28}$ Dizzy patients who declined to participate in the trial might, for example, have been older, with more comorbidities or less dizziness. Second, as $73.9 \%$ of the patients in the development cohort had an unfavorable course of dizziness (the outcome), the number of patients without the outcome was relatively small. We therefore internally validated the prediction model and corrected for overoptimism. Third, there was a considerable loss to follow-up, that is, missing data on the outcome. Exclusion of patients with missing values may cause biased results and decreases statistical efficiency. ${ }^{36}$ We therefore applied a multiple imputation technique in cases where the outcome was missing.

\section{Comparison With Existing Literature}

Literature on the prognosis of dizziness in older patients is scarce: only 1 previous study, by Dros et $\mathrm{al}_{1}{ }^{24}$ has presented a prediction model to assess dizziness prognosis in older people. In the current study, we identified dizziness-related impairment (based on DHI-S score) as a strong predictor for an unfavorable course of dizziness. Dros et a ${ }^{24}$ chose to exclude the DHI score from their final model because this score does not provide guidance for clinical interventions. By ignoring the strongest predictor, there was room in their model for other predictors having a smaller predictive ability for identifying patients with an unfavorable course of dizziness. This difference explains why our prediction model including the DHI-S score contains a different set of predictors.

Three other prospective cohort studies have examined predictors of persistent dizziness in older people. ${ }^{21,23,25}$ Two of those studies focused on predictors of dizziness in the long term (3- to 10-year follow-up), however. ${ }^{23,25}$ The third study investigated only univariate associations between potential predictors and dizziness. ${ }^{21}$ Our study distinguishes itself from the others by including only patients with substantial dizziness-related impairment. This inclusion criterion, together with differences in design and statistical methods, might explain why our final prediction model did not include previously identified predictors such as impaired mobility, ${ }_{1}^{21,23,24}$ depression, ${ }^{23,24}$ anxiety, ${ }_{1}^{23,24}$ and multiple prescribed drugs..$^{21,23-25}$

\section{Implications for Research and Practice}

With the presented risk score, primary care physicians will be able to easily detect older dizzy patients at high risk for an unfavorable course of dizziness. This identification could prompt the physician to consider targeting factors potentially contributing to dizziness in these high-risk patients, even when the cause is unclear. ${ }^{9,13,20-27}$ Two ongoing trials are investigating the effectiveness of a multifactorial intervention for factors contributing to dizziness in older adults. ${ }^{28,45}$ Future results of these studies may provide more specific guidance on multifactorial therapy that is effective in reducing dizziness symptoms.

To read or post commentaries in response to this article, see it online at http://www.AnnFamMed.org/content/16/5/428.

Submitted December 30, 2017; submitted, revised, June 1, 2018; accepted June 28, 2018.

Key words: dizziness; older adults; risk prediction; risk factors; falls; geriatrics; practice-based research; primary care

Acknowledgments: We thank all patients and primary care physicians who participated in the RODEO study. 
Funding support: This research project is funded by the Netherlands Organisation for Health Research and Development (project no. 839110001).

Disclaimer: The funding body did not have any role in trial design, collection, analysis, or interpretation of data, or in writing the manuscript.

Supplementary materials: Available at http://www.AnnFamMed. org/content/16/5/428/suppl/DC1/.

\section{References}

1. Maarsingh OR, Dros J, Schellevis FG, van Weert HC, Bindels PJ, Horst HE. Dizziness reported by elderly patients in family practice: prevalence, incidence, and clinical characteristics. BMC Fam Pract. 2010;11(2):2.

2. Stam $\mathrm{H}$, Harting $T$, Sluijs $M v$, et al. Usual care and management of fall risk increasing drugs in older dizzy patients in Dutch general practice. Scand J Prim Health Care. 2016;34(2):165-171.

3. Dros J, Maarsingh OR, Beem L, et al. Impact of dizziness on everyday life in older primary care patients: a cross-sectional study. Health Qual Life Outcomes. 2011;9(1):44.

4. Mueller M, Strobl R, Jahn K, et al. Impact of vertigo and dizziness on self-perceived participation and autonomy in older adults: results from the KORA-Age study. Qual Life Res. 2014;23(8): 2301-2308.

5. Olsson Möller U, Hansson EE, Ekdahl C, Midlöv P, Jakobsson U, Kristensson J. Fighting for control in an unpredictable life - a qualitative study of older persons' experiences of living with chronic dizziness. BMC Geriatr. 2014;14:97.

6. Stam H, Wisse M, Mulder B, van der Wouden JC, Maarsingh OR, van der Horst HE. Dizziness in older people: at risk of shared therapeutic nihilism between patient and physician. A qualitative study. BMC Fam Pract. 2016;17:74.

7. Tinetti ME, Williams CS, Gill TM. Health, functional, and psychological outcomes among older persons with chronic dizziness. J Am Geriatr Soc. 2000;48(4):417-421.

8. Deandrea S, Lucenteforte E, Bravi F, Foschi R, La Vecchia C, Negri E. Risk factors for falls in community-dwelling older people: a systematic review and meta-analysis. Epidemiology. 2010;21(5):658-668.

9. Sloane PD, Coeytaux RR, Beck RS, Dallara J. Dizziness: state of the science. Ann Intern Med. 2001;134(9 Pt 2):823-832.

10. Drachman DA, Hart CW. An approach to the dizzy patient. Neurology. 1972;22(4):323-334.

11. Sloane PD, Baloh RW. Persistent dizziness in geriatric patients. J Am Geriatr Soc. 1989;37(11):1031-1038.

12. Colledge NR, Barr-Hamilton RM, Lewis SJ, Sellar RJ, Wilson JA. Evaluation of investigations to diagnose the cause of dizziness in elderly people: a community based controlled study. BMJ. 1996; 313(7060):788-792.

13. Tinetti ME, Williams CS, Gill TM. Dizziness among older adults: a possible geriatric syndrome. Ann Intern Med. 2000;132(5):337-344.

14. Maarsingh OR, Dros J, Schellevis FG, et al. Causes of persistent dizziness in elderly patients in primary care. Ann Fam Med. 2010;8(3):196-205.

15. Verheij AAA, Van Weert $H$, Lubbers WJ, et al. The guideline 'Dizziness' of the Dutch College of General Practitioners [in Dutch]. Huisarts Wet. 2002;45(11):601-609.

16. The National Institute for Health and Care Excellence. Clinical knowledge summaries: vertigo [22-05-2017]. https://cks.nice.org. uk/vertigo. Accessed May 22, 2017.
17. McDonnell MN, Hillier SL. Vestibular rehabilitation for unilateral peripheral vestibular dysfunction. Cochrane Database Syst Rev. 2015; 1:CD005397.

18. Bhattacharyya N, Gubbels S, Schwartz S, et al. Clinical practice guideline: benign paroxysmal positional vertigo (update). Otolaryngol Head Neck Surg. 2017;156(3 suppl):S1-S47.

19. van Vugt VA, van der Horst HE, Payne RA, Maarsingh OR. Chronic vertigo: treat with exercise, not drugs. BMJ. 2017;358:j3727.

20. Kao AC, Nanda A, Williams CS, Tinetti ME. Validation of dizziness as a possible geriatric syndrome. J Am Geriatr Soc. 2001;49(1):72-75.

21. Gassmann KG, Rupprecht R; IZG Study Group. Dizziness in an older community dwelling population: a multifactorial syndrome. J Nutr Health Aging. 2009;13(3):278-282.

22. Gomez F, Curcio CL, Duque G. Dizziness as a geriatric condition among rural community-dwelling older adults. J Nutr Health Aging. 2011;15(6):490-497.

23. Maarsingh OR, Stam $H$, van de Ven PM, van Schoor NM, Ridd MJ, van der Wouden JC. Predictors of dizziness in older persons: a 10 -year prospective cohort study in the community. BMC Geriatr. 2014;14(1):133.

24. Dros J, Maarsingh OR, Beem L, et al. Functional prognosis of dizziness in older adults in primary care: a prospective cohort study. J Am Geriatr Soc. 2012;60(12):2263-2269.

25. Olsson Möller U, Midlöv P, Kristensson J, Ekdahl C, Berglund J, Jakobsson $\mathrm{U}$. Prevalence and predictors of falls and dizziness in people younger and older than 80 years of age-a longitudinal cohort study. Arch Gerontol Geriatr. 2013;56(1):160-168.

26. de Moraes SA, Soares WJ, Ferriolli E, Perracini MR. Prevalence and correlates of dizziness in community-dwelling older people: a cross sectional population based study. BMC Geriatr. 2013;13(4):4.

27. Kammerlind AS, Ernsth Bravell M, Fransson El. Prevalence of and factors related to mild and substantial dizziness in communitydwelling older adults: a cross-sectional study. BMC Geriatr. 2016; 16:159.

28. Stam H, van der Wouden JC, van der Horst HE, Maarsingh OR. Impairment reduction in older dizzy people in primary care: study protocol for a cluster randomised controlled trial. Trials. 2015; 16(313):313.

29. Jacobson GP, Newman CW. The development of the Dizziness Handicap Inventory. Arch Otolaryngol Head Neck Surg. 1990;116(4): 424-427.

30. Peduzzi P, Concato J, Kemper E, Holford TR, Feinstein AR. A simulation study of the number of events per variable in logistic regression analysis. J Clin Epidemiol. 1996;49(12):1373-1379.

31. Whitney SL, Wrisley DM, Brown KE, Furman JM. Is perception of handicap related to functional performance in persons with vestibular dysfunction? Otol Neurotol. 2004;25(2):139-143.

32. Tamber AL, Wilhelmsen KT, Strand LI. Measurement properties of the Dizziness Handicap Inventory by cross-sectional and longitudinal designs. Health Qual Life Outcomes. 2009;7:101.

33. Harun A, Agrawal Y. The use of fall risk increasing drugs (FRIDs) in patients with dizziness presenting to a neurotology clinic. Otol Neurotol. 2015;36(5):862-864.

34. Jacobson GP, Calder JH. A screening version of the Dizziness Handicap Inventory (DHI-S). Am J Otol. 1998;19(6):804-808.

35. Royston P, Moons KG, Altman DG, Vergouwe Y. Prognosis and prognostic research: Developing a prognostic model. BMJ. 2009; 338:b604.

36. van Buuren S. Flexible Imputation of Missing Data. Boca Raton, FL: CRC Press/Chapman \& Hall; 2012.

37. Marshall A, Altman DG, Holder RL, Royston P. Combining estimates of interest in prognostic modelling studies after multiple imputation: current practice and guidelines. BMC Med Res Methodol. 2009;9:57. 
38. Altman DG, Royston P. The cost of dichotomising continuous variables. BMJ. 2006;332(7549):1080.

39. Steyerberg EW, Vergouwe Y. Towards better clinical prediction models: seven steps for development and an $A B C D$ for validation. Eur Heart J. 2014;35(29):1925-1931.

40. Moons KG, Kengne AP, Woodward M, et al. Risk prediction models: I. Development, internal validation, and assessing the incremental value of a new (bio)marker. Heart. 2012;98(9):683-690.

41. Janssen KJ, Moons KG, Kalkman CJ, Grobbee DE, Vergouwe Y. Updating methods improved the performance of a clinical prediction model in new patients. J Clin Epidemiol. 2008;61(1):76-86.

42. Moons KG, Altman DG, Reitsma JB, et al. Transparent reporting of a multivariable prediction model for individual orognosis or diagnosis (TRIPOD): explanation and elaboration. Ann Intern Med. 2015; 162(1):W1-W73.
43. Altman DG, Vergouwe Y, Royston P, Moons KG. Prognosis and prognostic research: validating a prognostic model. BMJ. 2009; 338(338):b605.

44. Toll DB, Janssen KJ, Vergouwe Y, Moons KG. Validation, updating and impact of clinical prediction rules: a review. J Clin Epidemiol. 2008;61(11):1085-1094.

45. Menant JC, Migliaccio AA, Hicks C, et al. Tailored multifactorial intervention to improve dizziness symptoms and quality of life, balance and gait in dizziness sufferers aged over 50 years: protocol for a randomised controlled trial. BMC Geriatr. 2017;17(1):56.

\section{CHANGE-OF-ADDPESS FORM FANNALS OF FAMILY MEDICINE}

Please complete this form and mail to the following address or fax to Annals Circulation at 913-906-6080:

Annals of Family Medicine, Circulation Department, 11400 Tomahawk Creek Pkwy, Leawood, KS 66211-2680

Check if member of sponsoring organization:

$\begin{array}{ll}\square \text { AAFP } & \square \text { ABFM } \square \text { STFM } \square \text { ADFM } \\ \square \text { AFMRD } \square \text { NAPCRG } \square \text { CFPC }\end{array}$

ID number from label on your journal cover

OLD Information (Please print.)

Name

Company (if applicable)

Address (Street plus Apt or Ste)

City

Country Postal Code (9-digit ZIP for US)

Telephone

Fax

E-Mail
NEW Information (Please print.)

\begin{tabular}{ll}
\hline Name & \\
\hline Company (if applicable) & \\
\hline Address (Street plus Apt or Ste) & State \\
\hline Country & Postal Code (9-digit ZIP for US) \\
\hline Telephone & Fax \\
\hline E-Mail &
\end{tabular}

